\title{
Subacute pericardial abscess after aortic valve replacement: a case report
}

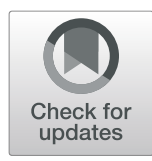

\author{
Ilenia Magnani ${ }^{1 \dagger}$, Alberto Spadotto ${ }^{1 \dagger}$, Pasquale Paolisso ${ }^{1}$, Alberto Foà ${ }^{1}$, Carlo Savini ${ }^{2}$, Davide Pacini², \\ Carmine Pizzi ${ }^{1 *}$ (D) and Nazzareno Galiè ${ }^{1+}$
}

\begin{abstract}
Background: Purulent pericarditis is an infectious disease, frequently caused by gram-positive bacteria, that is rarely observed in healthy individuals, and is often associated with predisposing conditions.

Case presentation: Here, we present the case of an Escherichia coli post-surgical localized purulent pericarditis complicated by transient constrictive pericarditis and its diagnostic and therapeutic management.

Conclusions: Our case report focuses on the importance of imaging-guided treatment of purulent pericardial diseases, in particular on the emerging role of 18 F-labelled 2-fluoro-2-deoxy-D-glucose Positron Emission Tomography/Computed Tomography in pericardial diseases and on the management of transient constrictive pericarditis, often seen after thoracic surgery.
\end{abstract}

Keywords: Pericardial abscess, Purulent pericarditis, Constrictive pericarditis, Escherichia coli

\section{Background}

Purulent pericarditis is defined as the presence of gross pus in the pericardium or microscopic purulence, frequently due to an infective agent; when localized, it becomes a pericardial abscess [1]. Today, in the antibiotic era, purulent pericarditis is rarely observed in healthy adults and the very few reported cases were associated with predisposing factors (immunodeficiency, alcohol abuse, cardiac surgery and chronic renal failure). The main cause is gram-positive bacteria and the typical clinical presentation is acute, with haemodynamic instability [2]. Clinical presentation might be subacute or chronic, usually caused by Mycobacterium tuberculosis [3]. However, uncommon cases of subacute purulent pericarditis due to Escherichia (E.) coli infection in patients with

\footnotetext{
* Correspondence: carmine.pizzi@unibo.it

${ }^{\dagger}$ Ilenia Magnani, Alberto Spadotto, Carmine Pizzi and Nazzareno Galiè contributed equally to this work.

${ }^{1}$ Department of Experimental, Diagnostic and Specialty Medicine-DIMES (Padiglione 23), University of Bologna, Via Giuseppe Massarenti 9, 40138 Bologna, Italy

Full list of author information is available at the end of the article
}

predisposing factors have been described [4]. We report a case of $E$. coli pericardial abscess in a patient who underwent cardiac surgery complicated by pericardial constriction.

\section{Case presentation}

In August 2017, a 61-year old man with multiple cardiovascular risk factors - obesity (BMI $30.8 \mathrm{~kg} / \mathrm{m}^{2}$ ), hypertension and hypercholesterolemia - underwent aortic valve replacement with a mechanical prosthetic valve for severe aortic stenosis. After surgery, the patient developed a persistent pericardial effusion and was discharged with steroidal therapy. Thereafter, the patient developed type 2 diabetes mellitus. Three months after surgery, the patient complained of exercise dyspnea with no clinical and laboratory signs of active infection. Transthoracic echocardiogram showed persistent pericardial effusion. In presence of post-pericardiotomy syndrome after cardiac surgery, an anti-inflammatory therapy with ibuprofen and colchicine was added on top of chronic steroidal therapy. 
In February 2018, he was referred to our hospital for rapidly worsening dyspnoea and lower limb oedema despite pharmacologic therapy. The patient denied fever and had no signs of haemodynamic instability, but the jugular venous pressure was about $12 \mathrm{~cm} \mathrm{H}_{2} \mathrm{O}$. His pulmonary examination was remarkable due to a decrease in breath sounds in both lung bases. Laboratory studies revealed elevated inflammatory markers (White Blood cell Count (WBC) 13,226/mmc, C-Reactive Protein (CRP) $13.91 \mathrm{mg} / \mathrm{dl}$, Procalcitonin (PCT) $1.5 \mathrm{ng} / \mathrm{ml}$ ).

A transthoracic echocardiogram showed a loculated pericardial effusion with signs of restrictive physiology, normal left ventricular function and no signs of valve dysfunction. Cardiac Computed Tomography (CT) confirmed the echocardiographic findings (Fig. 1a). To exclude an active infection, 18 F-labelled 2-fluoro-2-deoxy-D-glucose Positron Emission Tomography/Computed Tomography $\left({ }^{18} \mathrm{~F}\right.$-FDG PET/CT) was performed and revealed a selective hypercaptation of the tracer at the walls of the pericardial effusion $($ SUV max =11) (Fig. 1d). Despite the selective cardiac hypercaptation on ${ }^{18} \mathrm{~F}$-FDG PET/CT, urinary and blood cultures, abdominal ultrasound and pancolonscopy were performed and excluded other sources of infection.
Because of the location of the pericardial effusion, video-assisted thoracic surgery pericardial drainage was planned. During the procedure, pleural empyema and a pericardial abscess were revealed, so a conversion to a mini-thoracotomy approach was necessary in order to perform pericardiotomy and pleural decortication. After broad-spectrum antibiotic therapy, an amoxicillinsensitive E. coli was isolated from the pericardial fluid, so targeted intravenous antibiotics were continued for 2 weeks. The patient was discharged with oral amoxicillin/ clavulanate therapy aiming to complete a 4-week therapy.

In April 2018, the patient presented to the emergency department complaining of a high fever, worsening dyspnoea and lower limb oedema. An urgent CT scan revealed a paracardiac egg-shaped fluid collection (Fig. 1b). Laboratory tests only showed a mild elevation of inflammatory markers (WBC $11.780 / \mathrm{mmc}$, CRP $5.1 \mathrm{mg} / \mathrm{dl}$, PCT $0.4 \mathrm{ng} / \mathrm{ml}$ ). Empiric broad-spectrum antibiotic therapy and high dose diuretic therapy were started, and the patient was transferred to the Cardiology Department.

The echocardiogram showed a left postero-lateral fluid collection, without diffuse pericardial effusion. Cardiac magnetic resonance confirmed a non-homogeneous fluid collection, thick walls picking up contrast medium and

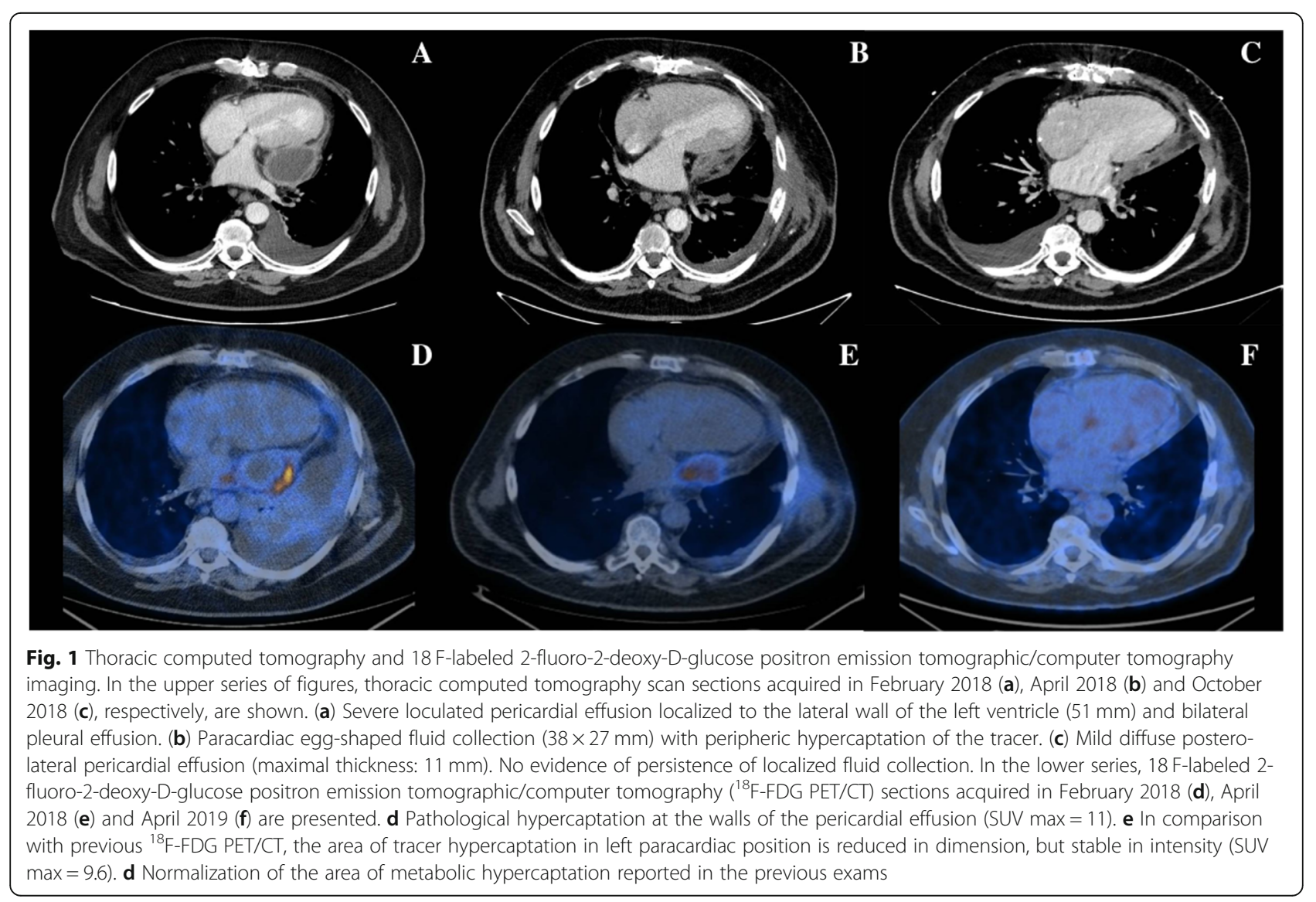


septal bounce. An ${ }^{18}$ F-FDG PET/CT revealed a persistence of tracer hypercaptation in the left paracardiac position (SUV 9.6 max) (Fig. 1e).

Due to the persistence of haemodynamic impairment, the patient underwent surgical excision of the pericardial abscess and partial pericardiectomy through a sternotomy approach. As shown in Fig. 2a the histological analysis demonstrated an underlying chronical inflammation process with fibrosis and mesothelial hyperplasia (Fig. 2b) and inflammatory infiltrate rich in macrophages (Fig. 2c). In the absence of microbial growth at microbiological exams, E. coli targeted intravenous antibiotic therapy was continued.

In considerations of the persistence of fluid overload and the new onset of signs of pericardial constriction at echocardiograms, high dose diuretic treatment and colchicine were successfully administered.

The patient was discharged home with long-term oral antibiotic therapy and colchicine.

At the 6- and 12-month evaluations, the patient was asymptomatic, without any symptoms of fluid overload or echocardiographic signs of constrictive physiology. A 6-month CT scan revealed the persistence of mild diffuse pericardial effusion without any sign of pericardial abscess (Fig. 1c). A 12-month 18-FDG-PET did not show any hypercaptation of the tracer in the cardiac area (Fig. 1f).

\section{Discussion and conclusions}

Despite optimized surgical technique and perioperative antibiotic prophylaxis, the incidence of infection after cardiac operations is still high [5]. We have described an unusual case of $E$. coli pericardial abscess in a postsurgical patient. The most common organism that causes purulent pericarditis is Staphylococcus aureus. Other frequently isolated bacteria are Neisseria meningitidis and Streptococcus pneumoniae. Gram-negative rods, Pseudomonas aeruginosa, Salmonella, anaerobes, and fungal pathogens are less common [6]. The literature contains few case-reports of purulent pericarditis due to a very uncommon gram-negative bacillus as $E$. coli. Sagrista-Sauleda et al. reported that in 33 patients with purulent pericarditis only two were due to E. coli [7] and usually develop in patients with cancer, in particular in aggressive lymphomas [4].

The development of postoperative cardiac infection may be due patient-related and procedure-related factors [8]. In our case report the elements related to the pericardial infection may be obesity and perhaps no optimal hygienic standards to minimize the local bacterial infection.

The clinical presentation in our patient was subacute/ chronic and differed from the acute manifestation of the vast majority of purulent pericarditis due to Gram + bacteria. This clinical evolution is probably typical of E.coli pericarditis [4] or might be due to a concomitant immunosuppression condition provoked by chronic antinflammatory therapy - steroidal and non-steroidal therapy - prescribed after cardiac surgery and the diabetic status. Our case report is the first described case of pericardial abscess due to $E$. coli after cardiac surgery. However, it is reported that purulent pericarditis is an unusual complication of thoracic surgery. Pericarditis may be present in the early post-operative period associated with a severe mediastinitis requiring re-operation and drainage. Our patient was discharged with steroidal and non-steroidal anti-inflammatory drugs, demonstrating that the pericarditis was already present, but it was diagnosed as post-pericardiectomy.

In our case, a very careful work-up was essential in guiding the diagnosis and treatment. In particular, ${ }^{18} \mathrm{~F}$ FDG PET/CT confirmed the persistence of the inflammation. In heart studies, ${ }^{18} \mathrm{~F}$-FDG PET/CT is used to identify areas of viable myocardium and inflamed tissues such as infiltrating inflammatory cells and infectious foci. Its efficacy is due to the ability of ${ }^{18}$ F-FDG PET/CT

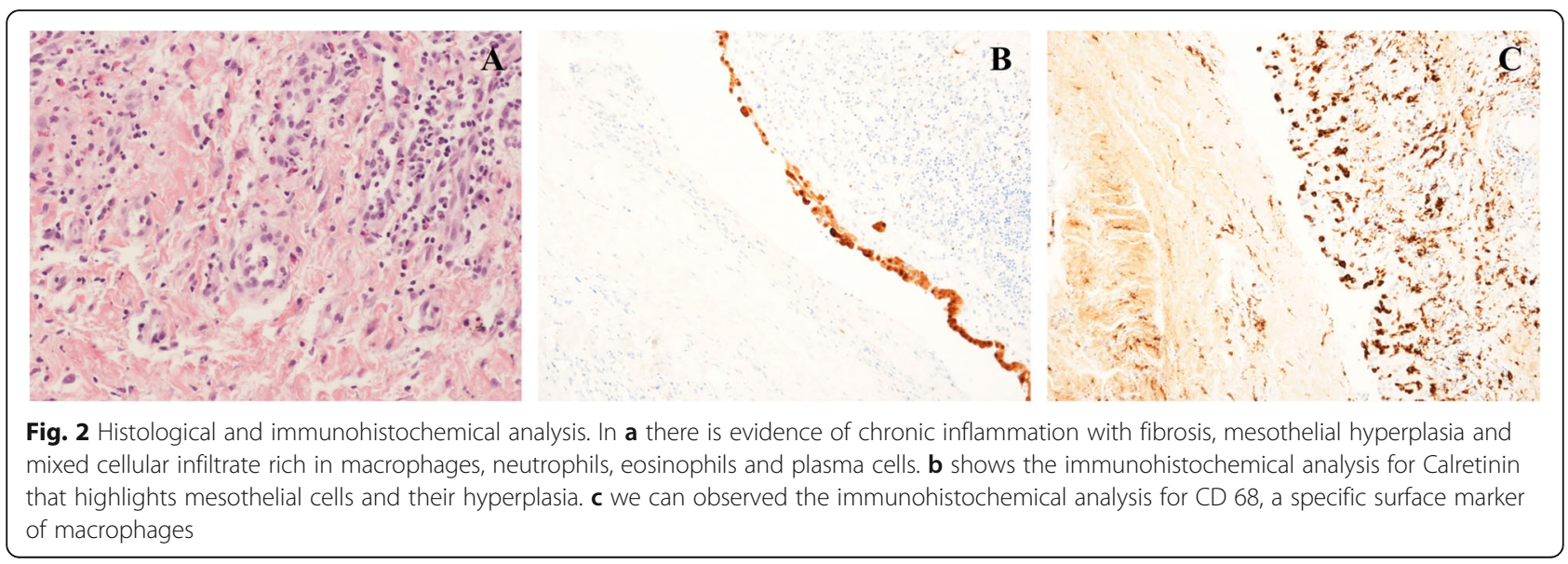


to dynamically penetrate activated leukocytes, macrophages, and CD4-positive $\mathrm{T}$ cells present at the sites of infection. In parallel, recent studies have reported promising data for ${ }^{18} \mathrm{~F}$-FDG PET/CT in the diagnosis of infective endocarditis particularly in patients with prosthetic valves and implantable cardiac electronic device infection as well as in the recognition of extracardiac complications [9]. The recent guidelines of the European Society of Cardiology have included ${ }^{18}$ F-FDG $\mathrm{PET} / \mathrm{CT}$ as a diagnostic tool in the diagnostic algorithm of prosthetic valve endocarditis [10].

A few studies and several case reports have demonstrated that ${ }^{18} \mathrm{~F}$-FDG PET/CT imaging provides a measurement of inflamed tissues such as purulent pericarditis. Intense ${ }^{18} \mathrm{~F}$-FDG PET/CT uptake has been described in tuberculous pericarditis on ${ }^{18} \mathrm{~F}$-FDG PET/ CT [11]. Dong et al. reported that ${ }^{18}$ F-FDG PET/CT in patients with purulent pericarditis had a greater intensity of uptake as compared with idiopathic pericarditis. In fact, in our patient's ${ }^{18}$ F-FDG PET/CT the SUV max was very high [12]. Despite pseudonormalised inflammatory markers, the correct non-invasive imagines helped us in deciding the correct management and the correct follow-up.

Finally, constrictive physiology developed in our patient immediately after pericardiectomy with an urgent need for intravenous diuretics and anti-inflammatory drugs, but almost disappeared at follow-up. In fact, transient constrictive pericarditis is frequently described in the literature after cardiac surgery and is related to the presence of acute inflammation that provokes constrictive symptoms and resolves after standard treatment for acute pericarditis [13].

In conclusion, this case report highlights the importance of the correct microbiological diagnosis in order to best guide antimicrobial therapy and the central role of imaging-guided treatment of purulent pericardial diseases. We also reported the existence of a transient form of constrictive pericarditis, often seen after thoracic surgery, which usually resolves with anti-inflammatory drugs.

\section{Abbreviations \\ E. coli: Escherichia coli; WBC: White Blood cell Count; CRP: C-Reactive Protein; PCT: Procalcitonin; CT: Computed Tomography; ${ }^{18} \mathrm{~F}-\mathrm{FDG}$ PET/CT : $18 \mathrm{~F}-$ labelled 2-fluoro-2-deoxy-D-glucose Positron Emission Tomography/Com- puted Tomography}

\section{Acknowledgements}

Not applicable.

\section{Authors' contributions}

I.M has designed and drafted the manuscript, was involved in acquisition of data and in technical and material support, has approved the submitted version (and any substantially modified version that involves the author's contribution to the study) and agrees both to be personally accountable for the author's own contributions and to ensure that questions related to the accuracy or integrity of any part of the work, even ones in which the author was not personally involved, are appropriately investigated, resolved, and the resolution documented in the literature. A.S. has designed and drafted the manuscript, was involved in acquisition of data and in technical and material support, has approved the submitted version (and any substantially modified version that involves the author's contribution to the study) and agrees both to be personally accountable for the author's own contributions and to ensure that questions related to the accuracy or integrity of any part of the work, even ones in which the author was not personally involved, are appropriately investigated, resolved, and the resolution documented in the literature. P. P was involved in critical revision of the manuscript, has approved the submitted version (and any substantially modified version that involves the author's contribution to the study) and agrees both to be personally accountable for the author's own contributions and to ensure that questions related to the accuracy or integrity of any part of the work, even ones in which the author was not personally involved, are appropriately investigated, resolved, and the resolution documented in the literature. A.F. was involved in critical revision of the manuscript, has approved the submitted version (and any substantially modified version that involves the author's contribution to the study) and agrees both to be personally accountable for the author's own contributions and to ensure that questions related to the accuracy or integrity of any part of the work, even ones in which the author was not personally involved, are appropriately investigated, resolved, and the resolution documented in the literature. C.S. was involved in critical revision of the manuscript for important intellectual content, has approved the submitted version (and any substantially modified version that involves the author's contribution to the study) and agrees both to be personally accountable for the author's own contributions and to ensure that questions related to the accuracy or integrity of any part of the work, even ones in which the author was not personally involved, are appropriately investigated, resolved, and the resolution documented in the literature. D.P. was involved in critical revision of the manuscript for important intellectual content, has approved the submitted version (and any substantially modified version that involves the author's contribution to the study) and agrees both to be personally accountable for the author's own contributions and to ensure that questions related to the accuracy or integrity of any part of the work, even ones in which the author was not personally involved, are appropriately investigated, resolved, and the resolution documented in the literature. C.P. was involved in case report design and study supervision, in critical revision of the manuscript for important intellectual content, has approved the submitted version (and any substantially modified version that involves the author's contribution to the study) and agrees both to be personally accountable for the author's own contributions and to ensure that questions related to the accuracy or integrity of any part of the work, even ones in which the author was not personally involved, are appropriately investigated, resolved, and the resolution documented in the literature. N.G. was involved in critical revision of the manuscript for important intellectual content, has approved the submitted version (and any substantially modified version that involves the author's contribution to the study) and agrees both to be personally accountable for the author's own contributions and to ensure that questions related to the accuracy or integrity of any part of the work, even ones in which the author was not personally involved, are appropriately investigated, resolved, and the resolution documented in the literature. All authors read and approved the final manuscript.

\section{Funding}

The authors received no financial support for the research, authorship, and/ or publication of this article.

\section{Availability of data and materials} Not applicable.

Ethics approval and consent to participate Not applicable.

\section{Consent for publication}

The patient signed the BMC infection disease consent form for publication of his personal data and images.

\section{Competing interests}

The authors declare that they have no competing interests. 


\section{Author details}

'Department of Experimental, Diagnostic and Specialty Medicine-DIMES (Padiglione 23), University of Bologna, Via Giuseppe Massarenti 9, 40138 Bologna, Italy. ${ }^{2}$ Cardiac Surgery Unit, Cardio-Thoracic-Vascular Department, S. Orsola Hospital, Alma Mater Studiorum - University of Bologna, Bologna, Italy.

Received: 24 June 2019 Accepted: 30 April 2020

Published online: 13 May 2020

\section{References}

1. Adler Y, Charron P, Imazio M, et al. 2015 ESC guidelines for the diagnosis and management of pericardial diseases: the task force for the diagnosis and Management of Pericardial Diseases of the European Society of Cardiology (ESC) endorsed by: the European Association for Cardio-Thoracic Surgery (EACTS). Eur Heart J. 2015:36:2921-64.

2. Parikh SV, Memon N, Echols M, Shah J, McGuire DK, Keeley EC. Purulent pericarditis: report of 2 cases and review of the literature. Medicine (Baltimore). 2009;88:52-65.

3. Mayosi BM, Burgess LJ, Doubell AF. Tuberculous pericarditis. Circulation. 2005;112:3608-16.

4. Horii $\mathrm{S}$, Yada $\mathrm{H}$, Ito $\mathrm{K}$, et al. A rare case of rush progression of purulent pericarditis by Escherichia coli in a patient with malignant lymphoma. Int Heart J. 2018;59:655-9.

5. Gelijns AC, et al. Management practices and major infections after cardiac surgery. J Am Coll Cardiol. 2014;64:372-81.

6. Pankuweit S, Ristic AD, Seferovic PM, Maisch B. Bacterial pericarditis: diagnosis and management. Am J Cardiovasc Drugs. 2005;5:103-12.

7. Sagristà-Sauleda J, Barrabés JA, Permanyer-Miralda G, Soler-Soler J. Purulent pericarditis: review of a 20-year experience in a general hospital. J Am Coll Cardiol. 1993;22:1661-5.

8. Fowler VG, O'Brien SM, et al. Clinical Predictors of Major Infections After Cardiac Surgery. Circulation. 2005;112(9 Suppl):1358-65.

9. Saby L, Laas O, Habib G, et al. Positron emission tomography/computed tomography for diagnosis of prosthetic valve endocarditis: increased valvular 18F-fluorodeoxyglucose uptake as a novel major criterion. J Am Coll Cardiol. 2013;61:2374-82.

10. Habib G, Lancelloti P, Antunes MJ, et al. Guidelines for the management of infective endocarditis. The task force for the management of infective endocarditis of the European Society of Cardiology (ESC) endorsed by: European Association for Cardio-Thoracic Surgery (EACTS), the European Association of Nuclear Medicine (EANM). Eur Heart J. 2015;36:3075-128.

11. Testempassi E, Kubota K, Morooka M, et al. Constrictive tuberculous pericarditis diagnosed using 18F-fluorodeoxyglucose positron emission tomography: a report of two cases. Ann Nucl Med. 2010;24:421-5.

12. Dong A, Dong H, Wang Y, Cheng C, Zuo C, Lu J. (18) F-FDG PET/CT in differentiating acute tuberculous from idiopathic pericarditis: preliminary study. Clin Nucl Med. 2013;38:e160-5.

13. Gentry J, Klein AL, Jellis CL. Transient constrictive pericarditis: current diagnostic and therapeutic strategies. Curr Cardiol Rep. 2016;18:41.

\section{Publisher's Note}

Springer Nature remains neutral with regard to jurisdictional claims in published maps and institutional affiliations.

Ready to submit your research? Choose BMC and benefit from:

- fast, convenient online submission

- thorough peer review by experienced researchers in your field

- rapid publication on acceptance

- support for research data, including large and complex data types

- gold Open Access which fosters wider collaboration and increased citations

- maximum visibility for your research: over $100 \mathrm{M}$ website views per year

At $\mathrm{BMC}$, research is always in progress.

Learn more biomedcentral.com/submissions 